\title{
ESTAQUIA DE RESEDÁ-NACIONAL (Physocalymma scaberrimum Pohl.) EM DIFERENTES SUBSTRATOS E CONCENTRAÇÕES DE AIB
}

\author{
CUTTINGS OF BRAZILIAN ROSE WOOD (Physocalymma scaberrimum Pohl.) \\ WITH DIFFERENT SUBSTRATES AND CONCENTRATIONS OF IBA
}

\author{
Edilene Aparecida Preti ${ }^{1}$ Lilian Yukari Yamamoto ${ }^{2}$ Carina Cardoso $^{3}$ \\ Gisele Silva de Aquino ${ }^{4}$ Vanessa dos Santos Paes ${ }^{5}$ Adriane Marinho de Assis ${ }^{6}$ \\ Maria Helena Machado ${ }^{7}$ Carmen Silvia Vieira Janeiro Neves ${ }^{8}$ Sérgio Ruffo Roberto ${ }^{9}$
}

\begin{abstract}
RESUMO
O resedá-nacional (Physocalymma scaberrimum Pohl.) é uma espécie nativa do Brasil que apresenta grande potencial para uso no paisagismo e em reflorestamento, além da madeira ser empregada na marcenaria de luxo. O objetivo deste trabalho foi avaliar o efeito de diferentes substratos e concentrações de ácido indolbutírico (AIB) na estaquia de resedá-nacional. O delineamento experimental foi o inteiramente casualizado, com cinco repetições em arranjo fatorial 3 x 3, sendo os fatores: tipos de substratos (areia de granulação média; casca de arroz carbonizada e vermiculita de granulação média) e concentrações de AIB ( $0 ; 1.000$ e 2.000 mg $\mathrm{L}^{-1}$ ), em parcelas compostas por dez estacas. Após 104 dias da instalação do experimento, foram avaliadas as seguintes variáveis: sobrevivência das estacas; retenção foliar; porcentagem de estacas com calos não enraizadas; estacas enraizadas; número de raízes por estaca; comprimento de raízes por estaca e massa seca das raízes por estaca. Não foram observadas diferenças quanto ao enraizamento em relação à aplicação de AIB, obtendo-se, em média, 23,5\%. Entre os substratos, embora as estacas enraizadas em areia e casca de arroz carbonizada tenham apresentado maior retenção foliar, todos os substratos testados podem ser utilizados.
\end{abstract}

Palavras-chave: estacas; enraizamento; regulador de crescimento; auxina.

\section{ABSTRACT}

The Brazilian rose wood is a native species from Brazil that has great potential for use in landscaping and reforestation, in addition to its use in luxury furniture. The objective of this work was to evaluate the effect of different substrates and concentrations of indole butyric acid (IBA) in the cutting of Brazilian resedá.

1. Engenheira Agrônoma, Mestranda do Programa de Pós-Graduação em Agronomia, Centro de Ciências Agrárias, Universidade Estadual de Londrina, Caixa Postal 6001, CEP 86051-990, Londrina (PR). Bolsista Capes. edipretti2006@yahoo.com.br

2. Engenheira Agrônoma, Msc., Doutoranda do Programa de Pós-Graduação em Agronomia, Centro de Ciências Agrárias, Universidade Estadual de Londrina, Caixa Postal 6001, CEP 86051-990, Londrina (PR). Bolsista CNPq. lilianyamamoto@yahoo.com.br

3. Engenheira Agrônoma, Mestranda do Programa de Pós-Graduação em Agronomia, Centro de Ciências Agrárias, Universidade Estadual de Londrina, Caixa Postal 6001, CEP 86051-990, Londrina (PR). Bolsista Capes. cari_ cardoso@hotmail.com

4. Engenheira Agrônoma, Mestranda do Programa de Pós-Graduação em Agronomia, Centro de Ciências Agrárias, Universidade Estadual de Londrina, Caixa Postal 6001, CEP 86051-990, Londrina (PR).

5. Engenheira Agrônoma, Universidade Estadual de Londrina, Caixa Postal 6001, 86051-990, Londrina, PR, Brasil.

6. Engenheira Agrônoma, Dr., Pós-doutoranda do Programa de Pós-Graduação em Agronomia, Centro de Ciências Agrárias, Caixa Postal 6001, CEP 86051-990, Londrina (PR). Bolsista PNPD - CAPES. agroadri@ig.com.br

7. Engenheira Agrônoma, Dr. pela Universidade Estadual de Londrina, Caixa Postal 6001, CEP 86051-990, Londrina (PR).maria_helena@uel.br

8. Engenheira Agrônoma, Dr., Professor Associado do Departamento de Agronomia, Universidade Estadual de Londrina, Caixa Postal 6001, CEP 86051-990, Londrina (PR). csvjneve@uel.br

9. Engenheiro Agrônomo, Dr., Professor Associado do Departamento de Agronomia, Universidade Estadual de Londrina, Caixa Postal 6001, CEP 86051-990, Londrina (PR) sroberto@uel.br

Recebido para publicação em 16/03/2010 e aceito em 26/04/2011 
The experiment had a randomized design in a 3x3 factorial arrangement with five replications, and each plot was composed by ten cuttings. The factors were types of substrates (washed mild sand; carbonized rice husk and vermiculite medium granules), and IBA (0 mg. $\mathrm{L}^{-1} ; 1,000 \mathrm{mg} . \mathrm{L}^{-1}$ and 2,000 mg. $\left.\mathrm{L}^{-1}\right)$. After 104 days, the following variables were evaluated: cutting survival; leaf retention; non-rooted cuttings with callus; rooted cuttings; root number per cutting; root length per cutting and dry root matter per cutting. There was no difference using IBA to improve the cuttings rooting, with average of $23.5 \%$ of rooting. Among the substrates, although the cuttings in sand and carbonized rice husk showed a better leaf retention, all substrates can be used.

Keywords: cuttings; rooting; growth regulators; auxin

\section{INTRODUÇÃO}

Pertencente à família Lythraceae, a espécie Physocalymma scaberrimum Pohl. é uma árvore nativa do Brasil, conhecida popularmente como resedá-nacional, pau-de-rosa ou nó-de-porco. Além de sua madeira ser empregada em marcenaria de luxo, a árvore é extremamente ornamental, principalmente quando em flor, sendo recomendada para o uso paisagístico e em reflorestamento (LORENZI, 2002).

A propagação sexuada pode ser empregada para a multiplicação dessa espécie. Entretanto, na propagação em escala comercial, em que se deseja multiplicar um genótipo que apresente características consideradas superiores e que se perdem quando propagadas por sementes devido à variabilidade, é imprescindível a adoção da propagação vegetativa, obtendo-se mudas geneticamente idênticas à plantamãe (FACHINELLO et al., 2005). No caso do resedá-nacional, entre as características desejáveis, podem ser citadas a abundância do florescimento e o tamanho das flores para o uso paisagístico, além do porte, do rápido desenvolvimento e da rusticidade.

Entre os métodos de propagação vegetativa, a estaquia é amplamente utilizada para multiplicação de algumas espécies florestais e frutíferas (TOFANELLI et al., 2002), permitindo a obtenção de plantas idênticas a partir de uma única planta-matriz, em curto espaço de tempo, além de ser uma técnica de baixo custo e fácil execução (FACHINELLO et al., 2005). No entanto, a habilidade de enraizamento difere entre as espécies, que são classificadas em espécies de fácil propagação, quando apresentam respostas crescentes ao enraizamento, desde que sejam proporcionadas condições adequadas de controle ambiental e manejo da fonte de propágulo vegetativo; e espécies com pequena ou nenhuma resposta aos estímulos para enraizamento (XAVIER, 2002).

Neste contexto, o substrato é um dos fatores que condiciona o sucesso no enraizamento das estacas, considerando-se como o meio ideal aquele que apresente boa porosidade, drenagem e capacidade de retenção de umidade (CARNEIRO, 1995; PASQUAL et al., 2001; SCHMITZ et al., 2002; HARTMANN e KESTER, 2002; FACHINELLO et al., 2005).

Além do substrato, o uso de fitorreguladores é uma prática largamente difundida e tem como finalidade aumentar a porcentagem de estacas enraizadas, acelerar esse processo, aumentar o número e a qualidade das raízes formadas e promover a uniformidade no enraizamento, podendo viabilizar a produção de mudas, especialmente em espécies de difícil enraizamento (FACHINELLO et al., 2005). Entre os fitorreguladores, o estímulo de auxinas na formação de raízes adventícias tem sido útil para a propagação por estaquia (TAIZ e ZEIGER, 2004). A eficiência do AIB vem sendo demonstrada para diferentes espécies, em função da menor mobilidade e maior estabilidade química, quando comparado ao ácido indolacético (AIA), além de ser menos fitotóxico, em comparação ao ácido naftalenoacético (ANA) (FACHINELLO et al., 2005; SARZI e PIVETTA, 2005).

Em muitas espécies florestais o enraizamento é maximizado pela aplicação de auxinas, como em Laurus nobilis L. (FOCHESATO et al., 2006), Olea europaea L. (OLIVEIRA et al., 2003), Theobroma cacao L. (LEITE e MARTINS, 2007) e Jasminum mesnyi (ALTHAUS et al., 2007). Contudo, a aplicação de auxina na base das estacas, até uma determinada concentração, promove o enraizamento; porém, a partir daquela, qualquer acréscimo tem efeito inibitório. $\mathrm{O}$ teor adequado de auxina exógena necessária para estimular o enraizamento depende da espécie e da concentração endógena do tecido (FACHINELLO et al., 2005).

Sendo assim, considerando o potencial do resedá-nacional como planta ornamental e a necessidade de desenvolver tecnologia de 
propagação, que permita a manutenção das características desejáveis, o objetivo deste trabalho foi avaliar a propagação vegetativa por estaquia de resedá-nacional, em diferentes substratos e concentrações de AIB.

\section{MATERIAL E MÉTODOS}

O experimento foi realizado no período de maio a agosto de 2009, no Centro de Ciências Agrárias da Universidade Estadual de Londrina (UEL), Estado do Paraná, localizada a $566 \mathrm{~m}$ de altitude, $23^{\circ} 23$, de Latitude Sul e $51^{\circ} 11$, de Longitude Oeste.

Foram utilizadas estacas herbáceas de 10$12 \mathrm{~cm}$, retiradas no dia 12/05/09, da parte mediana dos ramos de plantas matrizes de resedá-nacional, pertencentes à coleção de árvores da Universidade Estadual de Londrina.

Foram estudados três tipos de substratos (areia de granulação média; casca de arroz carbonizada e vermiculita de granulação média) e três concentrações de AIB $\left(0 ; 1.000\right.$ e $\left.2.000 \mathrm{mg} \mathrm{L}^{-1}\right)$.

Antes de efetuar a coleta das estacas foi preparada a solução hidroalcoólica do AIB, pesando-se $0,1 \mathrm{~g}$ de AIB em balança semianalítica, e dissolvendo-se em $50 \mathrm{~mL}$ de álcool em um becker, com auxílio de agitador eletromagnético. Após totalmente dissolvido o AIB, completou-se o volume para $100 \mathrm{~mL}$ com água destilada, obtendose então a concentração de $1.000 \mathrm{mg} \cdot \mathrm{L}^{-1}$ de AIB.

O preparo das estacas consistiu em um corte em bisel logo abaixo de um nó com a eliminação das folhas da parte basal, deixando-se um par de folhas na parte superior. Durante o preparo das estacas, estas foram dispostas provisoriamente em um recipiente com água para evitar a desidratação. Após o seu preparo, as estacas foram submetidas à aplicação de AIB, através de imersão rápida (5 segundos) da sua porção basal.

Em seguida, as estacas foram colocadas para enraizamento em caixas plásticas $(44 \times 30$ x $7 \mathrm{~cm}$ ), contendo os substratos, em câmara de nebulização, com regime intermitente controlado por temporizador e válvula solenóide programada para nebulizar as estacas durante 10 segundos a cada intervalo de 3 minutos. O bico nebulizador empregado (Modelo Mist DanSprinklers, Israel) apresentou vazão de $35 \mathrm{~L} /$ hora. A câmara de nebulização foi inserida em uma estufa com cobertura de filme de polietileno transparente e sombrite $30 \%$.
O delineamento experimental foi $\mathrm{o}$ inteiramente casualizado, com 5 repetições em arranjo fatorial $3 \times 3$ (três tipos de substratos e três concentrações de AIB) e cada parcela foi composta por 10 estacas. As estacas foram tratadas quinzenalmente com fungicidas sistêmicos à base de tebuconazol. Foi realizada adubação foliar quinzenalmente com fertilizante comercial Biofert $\operatorname{Plus}^{\circledR}$ (8-9-9 + micro) na proporção de $5 \mathrm{~mL} \mathrm{~L}^{-1}$.

Após 104 dias da instalação do experimento, foram avaliadas as seguintes varáveis: sobrevivência das estacas ( $\%$ de estacas vivas); retenção foliar (\% de estacas que não perderam as folhas); porcentagem de estacas com calos não enraizadas (\%); estacas enraizadas (\% que emitiram pelo menos uma raiz); número de raízes por estaca (consideradas apenas aquelas que se originaram diretamente da estaca); comprimento de raízes por estaca $(\mathrm{cm})$ e massa seca das raízes por estaca (g). A massa seca das raízes foi obtida através de sua secagem em estufa à temperatura de $55^{\circ} \mathrm{C}$, por 24 horas em estufa com circulação forçada de ar.

Os dados foram submetidos à análise de variância e a comparação das médias foi realizada pelo teste de Tukey a $5 \%$ de probabilidade. Efetuouse a transformação de dados segundo a equação arco-seno $\sqrt{\mathrm{x} / 100}$ para os dados em porcentagem e para o número de raízes por estaca, efetuou-se a transformação $\sqrt{\mathrm{x}+1}$.

\section{RESULTADOS E DISCUSSÃO}

Comrelaçãoà porcentagem de sobrevivência das estacas, não houve interação significativa entre os tipos de substratos e as concentrações de AIB, não sendo observadas diferenças significativas entre esses fatores (Tabela 1).

Endres et al. (2007), em experimento com estacas de pau-brasil (Caesalpinia echinata Lam.), verificaram que as concentrações de auxinas testadas não tiveram efeito sobre a sobrevivência das estacas enraizadas em vermiculita. Contudo, Gratieri-Sossella et al. (2008) obtiveram maior porcentagem de sobrevivência de miniestacas de corticeira do banhado (Erythrina crista-galli L.), mediante a aplicação de AIB.

Quanto à porcentagem de retenção foliar, houve interação significativa entre os fatores estudados (Tabela 1). Nos substratos areia e casca de arroz carbonizada, as médias foram superiores (de 15 a 18\%) quando as estacas não foram tratadas com AIB. Na vermiculita não foram observadas 
diferenças significativas entre as concentrações de AIB e a retenção foi muito baixa, de 0 a $4 \%$. Pacheco e Franco (2008) verificaram que a ausência de folhas é fator limitante no enraizamento de estacas de açoita-cavalo (Luehea divaricata Mart.), tendo em vista que $100 \%$ das estacas sem folha morreram, antes mesmo de enraizar. Os autores atribuem este fato à síntese de auxina e fotoassimilados pelas folhas, uma vez que, mesmo tendo sido obtidos valores baixos, a retenção foliar favoreceu o enraizamento adventício $(28,19 \%)$ e a sobrevivência das estacas $(28,19 \%)$. Entretanto, no presente trabalho, não houve influência da retenção foliar na taxa de sobrevivência e enraizamento das estacas de resedá-nacional.

Para as variáveis porcentagem de estacas com calos não enraizadas, porcentagem de estacas enraizadas, número de raízes por estaca, comprimento da raiz, massa seca de raízes por estaca, não houve interação significativa entre os tipos de substratos e as concentrações de AIB (Tabela 2).

Os resultados obtidos estão de acordo com Endres et al. (2007), que não verificaram diferenças nas concentrações de auxinas quanto à formação de calos nas estacas de pau-brasil (Caesalpinia echinata Lam.), mas relataram que o razoável potencial de formação de calo observado, acima de $20 \% \mathrm{em}$ média, sugere a possibilidade de emissão de raízes em longo prazo. De acordo com Fachinello et al. (2005), o calo é um tecido cicatricial, cuja formação representa o início do processo de regeneração.
Embora a formação do calo e o aparecimento das raízes sejam fenômenos independentes, na maioria dos casos são influenciados pelos mesmos fatores, e podem ocorrer simultaneamente. Ainda que não haja uma relação direta entre a formação de calo e o enraizamento, é possível que estacas com calo respondam mais facilmente ao uso de promotores exógenos de enraizamento, quando comparadas às estacas sem calo, além deste tecido servir como barreira protetora ao ataque de micro-organismos.

Em estudo realizado com castanha-de-cutia (Couepia edulis Prance), Leandro e Yuyama (2008) obtiveram maior porcentagem de enraizamento, sem utilização de AIB, seguido do tratamento com concentração de $6.000 \mathrm{mg} \mathrm{L}^{-1}$ de AIB. Para o cacaueiro (Theobroma cacao L.), Leite e Martins (2007) observaram que as concentrações em torno de $4.000 \mathrm{mg} \mathrm{kg}^{-1}$ promoveram as maiores porcentagens de sobrevivência e enraizamento, número de raízes e de brotações, e massa seca de raiz e de brotação; enquanto em concentrações menores que 2.000 mg kg-1 e maiores que $6.000 \mathrm{mg} \mathrm{kg}^{-1}$, promoveram menores respostas das características avaliadas. No entanto, Valmorbida e Lessa (2008) verificaram que na ausência de AIB, as estacas de nogueirado-japão (Gingko biloba) apresentaram menor taxa de enraizamento, quando comparadas àquelas que foram tratadas com $2.000 \mathrm{mg} \mathrm{L}^{-1}$ de AIB.

Segundo Fachinello et al. (2005), o teor adequado de auxina exógena depende da concentração existente no tecido para o estímulo do enraizamento. No entanto, tal estímulo ocorre

TABELA 1: Sobrevivência das estacas (\%) e retenção foliar (\%) de resedá-nacional, submetidas a diferentes substratos e concentrações de AIB. Londrina, PR, 2009.

TABLE 1: Cutting survival (\%) and leaf retention (\%) of Brazilian reseda, submited to different substrates and concentrations of IBA. Londrina, PR, 2009.

\begin{tabular}{|c|c|c|c|c|c|c|}
\hline & \multirow{2}{*}{ Substrato } & \multicolumn{3}{|c|}{ Concentrações de AIB $\left(\mathrm{mg} \mathrm{L}^{-1}\right)$} & \multirow{2}{*}{ Média } & \multirow{2}{*}{$\mathrm{F}$} \\
\hline & & 0 & 1.000 & 2.000 & & \\
\hline \multirow{3}{*}{ Sobrevivência das estacas $(\%)^{a}$} & Areia & 66,0 & 40,0 & 46,0 & 51,4 & \multirow{3}{*}{$0,27^{\text {ns }}$} \\
\hline & $\mathrm{CAC}$ & 47,5 & 50,0 & 60,0 & 53,1 & \\
\hline & Vermiculita & 37,5 & 60,0 & 38,0 & 43,3 & \\
\hline Média & & 51,5 & 49,1 & 48,0 & & \\
\hline $\mathrm{F}$ & & & $0,17^{\mathrm{ns}}$ & & & \\
\hline \multirow{3}{*}{ Retenção foliar $(\%)^{\mathrm{a}}$} & Areia & $18,0 \mathrm{Aa}$ & $0,0 \mathrm{Ba}$ & $0,0 \mathrm{Ba}$ & 6,4 & $6,84 * *$ \\
\hline & $\mathrm{CAC}$ & $15,0 \mathrm{Aa}$ & $0,0 \mathrm{Ba}$ & $0,0 \mathrm{Ba}$ & 4,6 & $6,38^{* *}$ \\
\hline & Vermiculita & $0,0 \mathrm{Ab}$ & $0,0 \mathrm{Aa}$ & 4,0 Aa & 1,7 & $1,00^{\text {ns }}$ \\
\hline Média & & 11,5 & 0,0 & 1,3 & & \\
\hline $\mathrm{F}$ & & $6,11 * *$ & $0,00^{\mathrm{ns}}$ & $1,14^{\mathrm{ns}}$ & & \\
\hline
\end{tabular}

Em que: Médias seguidas por letras iguais maiúsculas nas linhas e minúsculas nas colunas não diferem entre si pelo teste de Tukey $(p<0,05) .{ }^{\mathrm{ns}}=$ não significativo; $* *=$ significativo $(p<0,01){ }^{\mathrm{a}}=$ dados originais; CAC $=\mathrm{Casca}$ de arroz carbonizada. 
TABELA 2: Estacas com calos não enraizadas (\%), estacas enraizadas (\%), número de raízes por estaca, comprimento da raiz $(\mathrm{cm})$ e massa seca de raízes por estaca $(\mathrm{g})$ de resedá-nacional, submetidas a diferentes substratos e concentrações de AIB. Londrina, PR, 2009.

TABLE 2: $\quad$ Non-rooted cuttings with callus (\%), rooted cuttings (\%), root number per cutting, root length $(\mathrm{cm})$ and dry root matter per cutting $(\mathrm{g})$ of Brazilian reseda, submited to different substrates and concentrations of IBA. Londrina, PR, 2009.

\begin{tabular}{|c|c|c|c|c|c|c|}
\hline & \multirow{2}{*}{ Substrato } & \multicolumn{3}{|c|}{ Concentrações de AIB $\left(\mathrm{mg} \mathrm{L}^{-1}\right)$} & \multirow{2}{*}{ Média } & \multirow{2}{*}{$\mathrm{F}$} \\
\hline & & 0 & 1.000 & 2.000 & & \\
\hline \multirow{3}{*}{$\begin{array}{l}\text { Estacas com calo não } \\
\text { enraizadas }(\%)^{\mathrm{a}}\end{array}$} & Areia & 14,0 & 10,0 & 14,0 & 12,9 & \multirow{3}{*}{$2,70^{\mathrm{ns}}$} \\
\hline & CAC & 2,5 & 2,5 & 10,0 & 5,4 & \\
\hline & Vermiculita & 12,5 & 10,0 & 0,0 & 6,7 & \\
\hline Média & & 10,0 & 7,3 & 8,0 & & \\
\hline $\mathrm{F}$ & & & $0,48^{\text {ns }}$ & & & \\
\hline \multirow{3}{*}{ Estacas enraizadas $(\%)^{\mathrm{a}}$} & Areia & 38,0 & 12,5 & 12,0 & 21,4 & \multirow{3}{*}{$0,42^{\text {ns }}$} \\
\hline & CAC & 25,0 & 22,5 & 26,0 & 24,6 & \\
\hline & Vermiculita & 17,5 & 36,7 & 22,0 & 24,2 & \\
\hline Média & & 27,7 & 22,7 & 20,0 & & \\
\hline $\mathrm{F}$ & & & $0,20^{\mathrm{ns}}$ & & & \\
\hline \multirow{3}{*}{$\begin{array}{l}\text { Número de raízes por } \\
\text { estaca }^{\mathrm{a}}\end{array}$} & Areia & 1,95 & 1,44 & 1,87 & 1,77 & \multirow{3}{*}{$1,39^{\mathrm{ns}}$} \\
\hline & CAC & 1,48 & 1,43 & 1,04 & 1,30 & \\
\hline & Vermiculita & 1,96 & 2,18 & 2,30 & 2,16 & \\
\hline Média & & 1,80 & 1,64 & 1,74 & & \\
\hline $\mathrm{F}$ & & & $0,05^{\mathrm{ns}}$ & & & \\
\hline \multirow{3}{*}{ Comprimento da raiz $(\mathrm{cm})$} & Areia & 3,28 & 2,10 & 2,29 & 2,59 & \multirow{3}{*}{0,91 ns } \\
\hline & CAC & 4,14 & 2,50 & 3,87 & 3,53 & \\
\hline & Vermiculita & 3,38 & 3,61 & 3,24 & 3,38 & \\
\hline Média & & 3,58 & 2,66 & 3,13 & & \\
\hline $\mathrm{F}$ & & & $0,66^{\mathrm{ns}}$ & & & \\
\hline \multirow{3}{*}{$\begin{array}{l}\text { Massa seca de raízes por } \\
\text { estaca }(\mathrm{g})\end{array}$} & Areia & 0,004 & 0,003 & 0,002 & 0,003 & \multirow{3}{*}{$0,26^{\text {ns }}$} \\
\hline & CAC & 0,003 & 0,002 & 0,002 & 0,002 & \\
\hline & Vermiculita & 0,004 & 0,002 & 0,002 & 0,003 & \\
\hline Média & & 0,004 & 0,002 & 0,002 & & \\
\hline $\mathrm{F}$ & & & $1,75^{\mathrm{ns}}$ & & & \\
\hline
\end{tabular}

Em que: ${ }^{\text {ns }}=$ não significativo; ${ }^{\mathbf{a}}=$ dados originais; $\mathrm{CAC}=$ Casca de arroz carbonizada.

até uma determinada concentração, diferindo para cada espécie, a partir da qual o efeito passa a ser inibitório (ALVARENGA e CARVALHO, 1983).

Com relação aos substratos utilizados, Kämpf (2006) descreve que tanto a areia quanto a vermiculita e a casca de arroz carbonizada apresentam boa aeração, que é um importante atributo a ser considerado na escolha dos substratos. Stumpf et al. (1999), testando estes substratos no enraizamento de estacas de falso-cipreste (Chamaecyparis lawsoniana Parl.), também não observaram diferenças na porcentagem de enraizamento de estacas.

No que se refere às condições meteorológicas, durante a condução do experimento, foram registrados valores de temperatura mínima entre 5 a $17^{\circ} \mathrm{C}$, sendo que os valores de temperatura máxima oscilaram entre 16 a $34^{\circ} \mathrm{C}$ (Figura 1). A capacidade da estaca em emitir raízes está relacionada às condições ambientais, à época de realização da estaquia (KLEIN et al., 2000; LEANDRO e YUYAMA, 2008) e também ao potencial genético de enraizamento e às condições fisiológicas da planta matriz (FACHINELLO et al., 2005). No presente experimento, mesmo mantendo as estacas sob nebulização, os baixos índices de enraizamento podem ter sido influenciados pela temperatura ambiente em alguns períodos, cujas médias encontravam-se abaixo de $24^{\circ} \mathrm{C}$ (Figura 1), valor considerado ideal para estimular a divisão celular na área de enraizamento (HANSEN, 1989). 


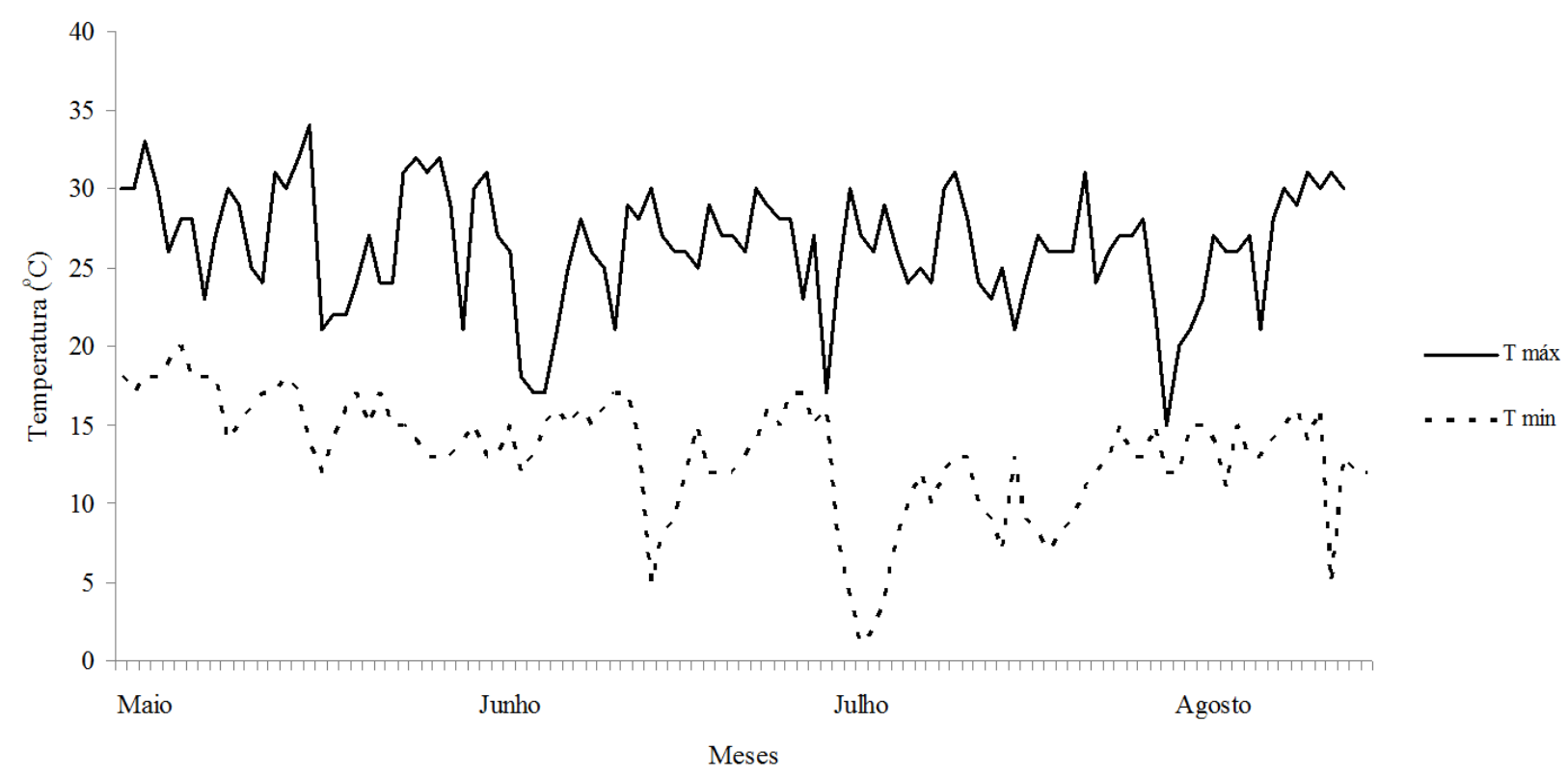

FIGURA 1: Médias referentes à temperatura $\left({ }^{\circ} \mathrm{C}\right)$ mínima (----) e máxima (---) na estufa, durante o período de condução do experimento (Maio a Agosto). Londrina, PR, 2009.

FIGURE 1: Averages for temperature $\left({ }^{\circ} \mathrm{C}\right)$ minimum (----) and maximum (---) in the greenhouse during the conduction of the experiment (May and August). Londrina, PR, 2009.

Com base nos resultados, foi possível verificar baixos índices de porcentagem de sobrevivência e capacidade de enraizamento das estacas nos diferentes substratos e concentrações de AIB, o que pode estar associado ao período de coleta das estacas e da realização deste experimento. Desta forma, novos estudos em outras épocas do ano devem ser realizados, buscando-se a otimização no enraizamento do resedá-nacional.

\section{CONCLUSÃO}

A propagação de resedá-nacional (Physocalymma scaberrimum) por estaquia pode ser realizada sem a utilização de AIB.

Os substratos areia, casca de arroz carbonizada e vermiculita apresentaram a mesma eficiência na propagação do resedá-nacional por estaquia.

\section{REFERÊNCIAS BIBLIOGRÁFICAS}

ALTHAUS, M. M. etal. Influência do ácido naftaleno acético e dois tipos de substrato no enraizamento de estacas de jasmim-amarelo. Revista Ciência Agronômica, v. 38, n. 3, p. 322-326, 2007.

ALVARENGA, L. R.; CARVALHO, V. D. Uso de substâncias promotoras de enraizamento de estacas de frutíferas. Informe Agropecuário, Belo
Horizonte, v. 9, n. 101, p. 47-55. 1983.

CARNEIRO, J. G. de A. Produção e controle de qualidade de mudas florestais. Curitiba: UFPR/ FUPEF; Campos: UENF, 1995. $451 \mathrm{p}$.

ENDRES, L. et al. Enraizamento de estacas de Pau-Brasil (Caesalpinia echinata Lam.) tratadas com ácido indol butírico e ácido naftaleno acético. Ciência Rural, Santa Maria, v. 37, n. 3, jun. 2007. FACHINELLO, J. C; HOFFMANN, A.; NACHTGAL, J. C. Propagação de plantas frutíferas. Brasília: Embrapa Informações Tecnológicas, 2005. $221 \mathrm{p}$.

FOCHESATO, M. L. et al. Propagação de louro (Laurus nobilis L.) por estacas semilenhosas com diferentes quantidades de folhas e tratadas com ácido indolbutírico. Revista Brasileira de Plantas Medicinais, Botucatu, v. 8, n. 3, p. 72-77, 2006. GRATIERI-SOSSELLA, A. et al. Propagação da corticeira do banhado (Erythrina crista-galli L.) (FABACEAE) pelo processo de estaquia. Revista Árvore, Viçosa, v. 32, n. 1, fev. 2008.

HANSEN, J. Influence of position and temperature during rooting of adventitious root formation and axilary bud break of Stephanotis floribunda. Scientia Horticulturae, Amsterdam, v. 40, n. 4, p. 345-354, 1989.

HARTMANN, H. T.; KESTER, D. E. Plant propagation: principles and practices. $7^{\text {th }}$ ed. New Jersey: Prentice-Hall, 2002, 880 p. 
KÄMPF, A. N.; TAKANE, R. J.; SIQUEIRA, P. T. V. Floricultura: técnicas de preparo de substratos. Brasília: LK, 2006. 132 p.

KLEIN, J. D.; COHEN, S.; HEBBE, Y. Seasonal variation in rooting ability of myrtle (Myrtus communis L.) cuttings. Scientia Horticulture, Amsterdam, v. 83, n. 1, p. 71-76, 2000.

LEANDRO, R. C.; YUYAMA, K. Enraizamento de estacas de castanha-de-cutia com uso de ácido indolbutírico. Acta Amazonica, Manaus, v. 38, n. 4, dez. 2008.

LEITE, J. B. V.; MARTINS, A. B. G. Efeito do ácido indolbutírico e época de coleta no enraizamento de estacas semi-lenhosas do cacaueiro. Revista Brasileira de Fruticultura. v. 29, n. 2, 2007.

LORENZI, H. Árvores Brasileiras: manual de identificação e cultivo de plantas arbóreas nativas do Brasil 2. ed, Nova Odessa: Plantarum, 2002. 384 p. v.2.

OLIVEIRA, A. F. et al. Enraizamento de estacas semilenhosas de oliveira sob efeito de diferentes épocas, substratos e concentrações de ácido indolbutírico. Ciência e Agrotecnologia, Lavras, v. 27, n. 1, p. 117-125, jan-fev., 2003.

PACHECO, J. P.; FRANCO, E. T. H. Substratos e estacas com e sem folhas no enraizamento de Luehea divaricata Mart. Ciência Rural, Santa Maria, v. 38, n. 7, p. 1900-1906, out. 2008.

PASQUAL, M. et al. Fruticultura comercial: propagação de plantas frutíferas. Lavras: UFLA/ FAEPE, 2001. $137 \mathrm{p}$.
SARZI, I.; PIVETTA, K. F. L. Efeito das estações do ano e do ácido indolbutírico no enraizamento de estacas de variedades de minirroseira (Rosa spp.). Científica, Jaboticabal, v. 332, n. 1, p. 62-68, 2005. SCHMITZ, J. A. K.; SOUZA, P. V. D.; KÄMPF, A. N. Propriedades químicas e físicas de substratos de origem mineral e orgânica para o cultivo de mudas em recipientes. Ciência Rural, Santa Maria, v. 32, n. 6, p. 937-944, 2002.

STUMPF, E. R. T.; GROLLI, P. R.; SILVA, J. A. G. da. Enraizamento de estacas de Chamaecyparis lawsoniana Parl. em cinco substratos com uso de ácido indolbutírico. Ciência Rural, Santa Maria, v. 29, n. 2, p. 207-211, jun. 1999.

TAIZ, L.; ZEIGER, E. Fisologia vegetal. 3. ed. Porto Alegre: Artmed Editora, 2004. 719 p.

TOFANELLI, M. B. D.; ONO, E. O.; RODRIGUES, J. D. Potencial de enraizamento de estacas lenhosas de pessegueiro tratadas com ácido indol-butírico em diferentes concentrações e métodos de aplicação. Revista Brasileira de Agrociência, v. 8, n. 2, p. 159-160, maio/ago, 2002.

VALMORBIDA, J.; LESSA, A. O. Enraizamento de estacas de Ginkgo biloba tratadas com ácido indolbutírico e ácido bórico. Ciência e agrotecnologia, Lavras, v. 32, n. 2, abr. 2008

XAVIER, A. Silvicultura clonal I: Princípios e técnicas de propagação vegetativa. Viçosa: Universidade Federal de Viçosa, 2002. 64p. (Caderno Didático, 92). 